UNIVERSIDADE FEDERAL DO RIO GRANDE DO SUL COLÉGIO DE APLICAÇÃO
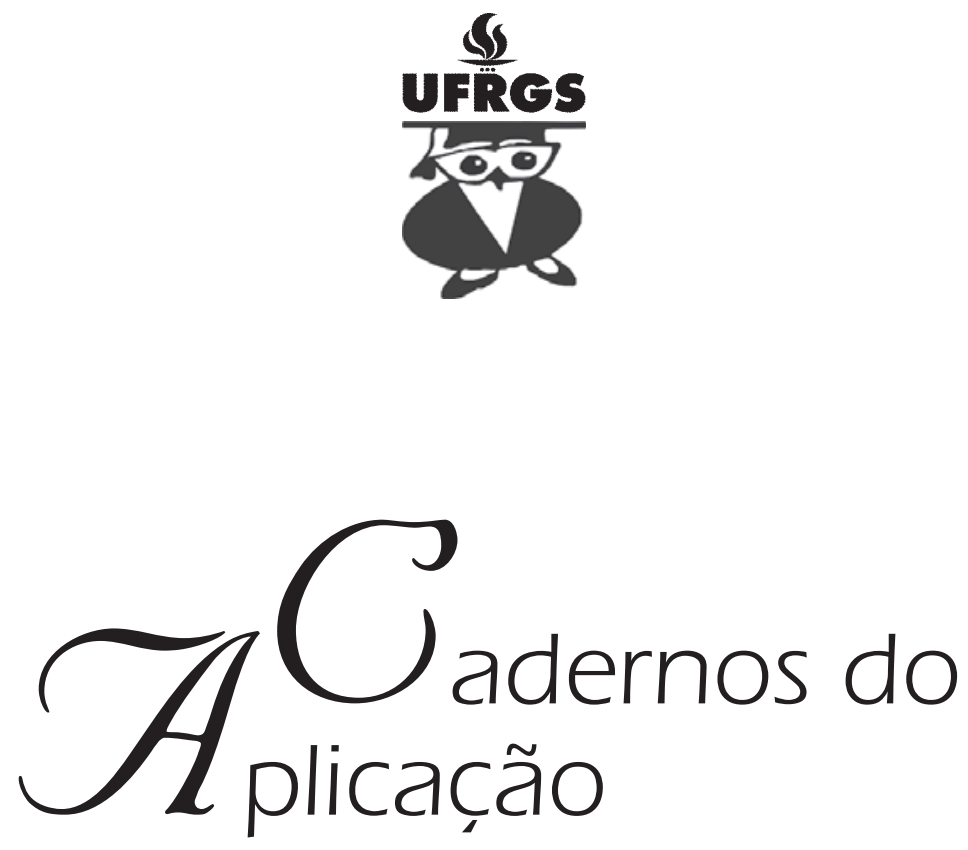

Temática especial:

O ensino de línguas na Educação Básica

Porto Alegre

v. 24, n. 1, janeiro a junho de 2011 


\section{UNIVERSIDADE FEDERAL DO RIO GRANDE DO SUL COLÉGIO DE APLICAÇÃO}

Reitor: Carlos Alexandre Netto

Vice-Reitor: Rui Vicente Oppermann

Diretor: Edson Luiz Lindner

Vice-Diretora: Lúcia Couto Terra

Editor: Tadeu Rossato Bisognin

Conselho Editorial: Adriana Dorfman (UFRGS), Airton Carrião (UFMG), Antonio Carlos Castrogiovanni (UFRGS), Diógenes Buenos Aires de Carvalho (UEMA), Edson Luiz Lindner (UFRGS), Gláucia Regina Raposo de Souza (UFRGS), Ítalo Modesto Dutra (UFRGS), Jaqueline Engelmann (UFRGS), João Francisco Duarte Jr. (UNICAMP), João Vicente Silva Souza (UFRGS), José Carlos Pinto Leivas (ULBRA), José Maria Soares Rodrigues (UFPA), Júlio Roberto Groppa Aquino (USP), Karen Elisabete Rosa Nodari (UFRGS), Léa da Cruz Fagundes (UFRGS), Lia Beatriz de Lucca Freitas (UFRGS), Ligia Beatriz Goulart (FACOS), Luciana Rossato (UDESC), Milton Mariani (UFMS), Mônica Baptista Pereira Estrázulas (UFRGS), Mônica Lima (UFRJ), Neiva Otero Schaffer (UFRGS), Regina Maria Varini Mutti (UFRGS), Rosalia Procasko Lacerda (UFRGS), Rosane Nunes Garcia (UFRGS), Rossano Pecoraro (PUC-RJ), Simone Vacaro Fogazzi (UFRGS), Tadeu Rossato Bisognin (UFRGS), Vanderlei Machado(UFRGS), Vera Teixeira de Aguiar (PUC-RS), Wagner de Campos Sanz (UFG)

Comissão Editorial: Adauto Locatelli Taufer, Aglaé Castilho Oliva, Demétrio Alves Paz, Marcello Paniz Giacomoni, Tadeu Rossato Bisognin, Vanderlei Machado

Capa: Telmo Remião Moure

Editoração Eletrônica: Carolina Rodrigues Lobato

Revisão: Felipe Raskin Cardon

Fonte Indexadora: Bibliografia Brasileira de Educação - Brasília: INEP / MEC

Latin American Periodicals Tables (LPTOC)

Apoio: Programa de Apoio à Editoração de Periódicos / PROPESQ / UFRGS ISSN 0103-6041

CADERNOS DO APLICAÇÃO/Universidade Federal do Rio Grande do Sul. Colégio de Aplicação. - v. 1, n. 1 (jan./jun. 1986)

Periodicidade semestral 1986 - 2011 v. 24 n. 1

Ensino Fundamental e Médio

CDU 373.3/5. (05)

Endereço para correspondência:

Colégio de Aplicação/UFRGS

Av. Bento Gonçalves, 9500 - Bairro Agronomia

Porto Alegre/RS - CEP 91501-970 - Fone: (51) 33086977 - Fax: (51) 33086976

E-mail: cap@cap.ufrgs.br

URL: http://www.cap.ufrgs.br/ cadernos

Outros acessos: http://www.seer.ufrgs.br/index.php/CadernosdoAplicacao/index e www.periodicos.ufrgs.br 


\section{Sumário}

Editorial

Apresentação do dossiê temático

Sim, Língua Estrangeira se aprende na escola

Henry Daniel Lorencena Souza, Rosália Lacerda

\section{Temática Especial}

\section{O ensino de línguas na Educação Básica}

O ensino da Língua Estrangeira através da literatura Ivana Kátia de Souza Ferreira, Laura Nelly Mansur Serres.

O ensino de línguas na escola e a formação de leitores

Henry Daniel Souza

Ensino de Língua Inglesa na Educação Básica: Cultura

e Vocabulário como portas (de abrir)

Vivian Albertoni.

"Mas dry não é seco em inglês?" O efeito de evidência de sentido para o sujeito entre línguas materna e estrangeira Giovani Forgiarini Aiub

La frontera entre Uruguay y Brasil y la realidad del español en comunidades fronterizas Hugo Jesús Correa Retamar, Clandia Stella Risso

O ensino de línguas estrangeiras no Colégio de Aplicação da UFRGS - destaque para a língua alemã Rosita Maria Schmitz.

\section{Pesquisa em Educação Básica}

Jogos digitais: uma abordagem educacional à luz da epistemologia genética Maria Leticia Felicori Tonelli Teixeira Leite, Patricia Schäfer, Daniela Szabluk, Helvia Bastos, Suzana Macedo, Mauricio Amorim, Rodney Albuquerque, Eliane Agniar, Lea Fagundes 
Desenhos animados em sala de aula: Tom e Jerry e Bob Esponja Calça Quadrada, uma análise comparativa

Rosana Fachel de Medeiros

Processos de tomada de consciência e reflexões acerca de "valores" em jogos de regras de caráter coletivo Stela Maris Vaucher Farias, Maria Luiza Rheingantz Becker

Uma investigação sobre a importância das aulas práticas de Biologia no Ensino Médio

Daniela Bonzanini de Lima, Rosane Nunes Garcia

Competências e habilidades no contexto da sala de aula:

ensaiando diálogos com a teoria piagetiana

Roselane Zordan Costella

\section{Relatos de Experiências}

Uma experiência de educação sexual em turmas de sétimo ano

Fábio Luiz Silva

Habilidades sociais na infância: uma experiência nos Anos Iniciais

Fernanda Vebber, Alessandra Bencke Jardim

Leitura e escrita na escola: possibilidades e atravessamentos de uma experiência na produção de livro Andrea da Paixão Fernandes, Jacqueline de Fatima dos Santos Morais, Lincoln Tavares Silva, Patrícia Braun

Charges e histórias em quadrinhos através da composição de imagens: estratégias de ensino na Educação Básica em Geografia Fernando Frederico Bernardes

Sobre os ciclos de formação e sobre o ensino seriado Valter Morigi 295

\section{Projetos de Pesquisa}

Ações afirmativas e o acesso à UFRGS:

subsídios para uma avaliação

João Vicente Silva Souza 
Desenvolvimento de um modelo de intervenção para a construção de conceitos de matemática via projetos de iniciação científica

Eduardo Britto Velho de Mattos.

Do papel à película: transposição da narrativa literária à fílmica por alunos do Ensino Médio Adauto Locatelli Tanfer

O gênero debate a serviço da capacidade de análise crítica, da autonomia e do posicionamento eficaz

Daniela Favero Netto

\section{Dos cadernos dos alunos}

La primavera

Alunos do $4^{\circ}$ ano

\section{Um Pouco de História}

Discurso de formatura da turma 112/1989

Fabricio Carpi Nejar

Índice de títulos 



\section{Editorial}

Ao conhecer outra(s) cultura(s), outra(s) forma(s) de encarar a realidade, os alunos passam a refletir, também, muito mais sobre a sua própria cultura e ampliam a sua capacidade de analisar o seu entorno social com maior profundidade, tendo melhores condições de estabelecervinculos, semelhanças e contrastes entre a sua forma de ser, agir, pensar e sentiv a de outros povos, enriquecendo a sua formação. (Parâmetros curriculares nacionais, códigos e suas tecnologias. Lingua estrangeira moderna.) *

Aprender uma língua é traduzir-se para novos modos de ver o mundo, pensar de alguma outra forma ou simplesmente transferir novos códigos convencionados para os mesmos conceitos. Sabe-se que quanto mais utilidade ou significado percebemos no estudo de qualquer conhecimento, mais nos interessamos em aprendê-lo. Exemplo disso é o estudo de qualquer língua estrangeira que possamos fazer no país onde ela é falada, porque dela muito precisamos. Tudo é interessante na aprendizagem de tal idioma porque a comunicação exige dominar muito mais que palavras. Como fica, então, a tarefa dos professores de Língua Estrangeira nas nossas escolas, onde a comunicação se faz em português? Quantos desafios eles devem enfrentar para cativar os alunos para aumentarem as possibilidades de ver o mundo pelo uso de outro idioma? Quais estratégias usar para motivar estudantes ainda desinteressados na aquisição de nova expressão como recurso para pensar? Pois este número dos Cadernos traz como Temática Especial o Ensino das Linguas Estrangeiras na Educação Básica. É um dossiê organizado pelos professores Henry Daniel Lorencena Souza e Rosália Lacerda Prochaska,

BRASIL, Ministério da Educação, Secretaria de Educação Média e Tecnológica. Parâmetros curriculares nacionais, códigos e suas tecnologias. Língua estrangeira moderna. Brasília: MEC, 1999. p. 49-63. 
ambos do Colégio de Aplicação, a quem muito agradecemos. Eles nos trazem reflexões e relatos de como estudar outro idioma em consonância com os tempos em que vivemos.

Neste número iniciamos a publicação de uma nova seção na Revista, Projetos de Pesquisa, um espaço reservado à publicação dos projetos de pesquisa desenvolvidos em Educação Básica. Inicialmente publicaremos os projetos em andamento dos professores do Colégio de Aplicação da UFRGS, em seguida, os projetos de todos os que se dedicam a investigações nesse nível de ensino. Serão divulgados também os projetos dos nossos alunos participantes do Programa Institucional de Bolsas de Iniciação Científica para o Ensino Médio - PIBIC EM, programa implantado no CAp/UFRGS em 2011. Como vemos, nossa revista espera cada vez mais ser um instrumento útil para debate e crítica, permitindo troca de experiências para transformação das práticas escolares.

Tadeu Rossato Bisognin 